\title{
Predictive modelling of interventions to improve iodine intake in New Zealand
}

\author{
Sonja Schiess ${ }^{1}$, Peter J Cressey ${ }^{2}$ and Barbara M Thomson 2 ,* \\ ${ }^{1}$ German Institute of Human Nutrition (DIFE) Potsdam-Rehbrücke, Nuthetal, Germany: ${ }^{2}$ Institute of Environmental \\ Science \& Research Ltd, PO Box 29 181, Christchurch 8540, New Zealand
}

Submitted 3 May 2011: Accepted 8 December 2011: First published online 25 January 2012

\begin{abstract}
Objective: The potential effects of four interventions to improve iodine intakes of six New Zealand population groups are assessed.

Design: A model was developed to estimate iodine intake when (i) bread is manufactured with or without iodized salt, (ii) recommended foods are consumed to augment iodine intake, (iii) iodine supplementation as recommended for pregnant women is taken and (iv) the level of iodization for use in bread manufacture is doubled from $25-65 \mathrm{mg}$ to $100 \mathrm{mg}$ iodine/ $\mathrm{kg}$ salt.

Setting: New Zealanders have low and decreasing iodine intakes and low iodine status. Predictive modelling is a useful tool to assess the likely impact, and potential risk, of nutrition interventions.

Subjects: Food consumption information was sourced from $24 \mathrm{~h}$ diet recall records for 4576 New Zealanders aged over 5 years.

Results: Most consumers (73-100\%) are predicted to achieve an adequate iodine intake when salt iodized at $25-65 \mathrm{mg}$ iodine $/ \mathrm{kg}$ salt is used in bread manufacture, except in pregnant females of whom $37 \%$ are likely to meet the estimated average requirement. Current dietary advice to achieve estimated average requirements is challenging for some consumers. Pregnant women are predicted to achieve adequate but not excessive iodine intakes when $150 \mu \mathrm{g}$ of supplemental iodine is taken daily, assuming iodized salt in bread.

Conclusions: The manufacture of bread with iodized salt and supplemental iodine for pregnant women are predicted to be effective interventions to lift iodine intakes in New Zealand. Current estimations of iodine intake will be improved with information on discretionary salt and supplemental iodine usage.
\end{abstract}

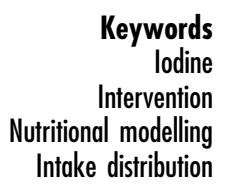

Iodine is an essential element in thyroid hormones required for normal growth and metabolism of tissues such as the central nervous system and for maintaining energy production and metabolic rate ${ }^{(1)}$. Iodine deficiency may lead to goitre, hypothyroidism, and impaired mental and physical development. Excess iodine intake may lead to enlargement of the thyroid gland and elevated production of thyroid-stimulating hormone. Dietary iodine requirements increase from childhood to adulthood, with the greatest requirement being for lactating and pregnant women ${ }^{(1)}$.

New Zealand is considered to have low-iodine soils resulting in low concentrations in locally grown foods ${ }^{(1)}$. Iodine-deficiency goitre was endemic in New Zealand by the early 1900 s before the iodization of salt in $1924^{(2)}$. Estimated dietary intake of iodine in New Zealand has decreased over the past 25 years due to decreased use of iodine-containing disinfectants in the dairy industry and changing food consumption patterns ${ }^{(3)}$. Estimated average iodine intake is low for most New Zealanders, ranging from 40 to $57 \%$ of the recommended daily intake across eight population groups based on Total Diet Surveys ${ }^{(3)}$. Low iodine intake is consistent with evidence of low and decreasing urinary iodide levels and hence iodine status ${ }^{(4-7)}$.

The use of iodized salt, containing between 25 and $65 \mathrm{mg}$ iodine $/ \mathrm{kg}$ salt, was mandated in the manufacture of bread in New Zealand in September 2009 as a major step towards redressing the low iodine status of New Zealanders $^{(8)}$. This intervention is consistent with WHO recommendations to use iodized salt to control iodine deficiency ${ }^{(9)}$. Further interventions include advice on food sources of iodine (seafood, iodized salt, seameal custard, milk and eggs) ${ }^{(10)}$ and supplementation for pregnant women ${ }^{(11)}$.

Previous iodine dietary intake assessments for New Zealand were deterministic, based on $14 \mathrm{~d}$ simulated $\operatorname{diets}^{(3)}$. While this approach provides population-average dietary intakes it does not provide information on the 
likely distribution of intake and thus the proportion of consumers who may be at risk from either too little or too much iodine. More informative modelling of the effectiveness of dietary interventions may be achieved using individual $24 \mathrm{~h}$ diet records, as applied to folic acid issues $^{(12,13)}$.

A model was developed to assess (i) the potential impact of replacing non-iodized with iodized salt in bread manufacture, (ii) the amount of single foods that are sources of iodine to be eaten to meet dietary guidelines for iodine, (iii) the potential impact of supplementation for pregnant women and (iv) the potential impact of further raising the level of salt iodization for use in bread manufacture, on the usual iodine intake for six New Zealand population groups over 5 years of age.

\section{Methods}

\section{Food consumption surveys}

Food consumption information was drawn from the 1997 National Nutrition Survey (NNS) ${ }^{(14)}$ that included 4636 nationally representative New Zealand respondents aged 15 years and older. Respondents participated in an individual interview to capture $24 \mathrm{~h}$ diet recall information, a self-administered qualitative FFQ including questions relating to food preparation habits and a physical examination. Repeat data were obtained for approximately $15 \%$ of respondents, interviewed on a second day. Food consumption information for children aged 5 to 14 years was taken from the 2002 National Children's Nutrition Survey (CNS) ${ }^{(15)}$ that captured $24 \mathrm{~h}$ diet recall information, with repeat data for $15 \%$ of respondents, and data on eating patterns of 3275 respondents. Interview days were randomized across days of the week and time of the year, for both studies, to remove potential biases. The two complete sets of dietary exposure estimates were divided to provide information on six groupings that most closely align with New Zealand dietary reference value guideline groups $^{(1)}$, namely (i) $\geq 25$-year-old males, (ii) 19-24-yearold males, (iii) $\geq 15$-year-old females (non-pregnant), (iv) $\geq 15$-year-old females (pregnant), (v) 9-13-year-old boys/ girls and (vi) 5-8-year-old children.

\section{Concentration of iodine in foods}

Mean iodine concentrations in 266 New Zealand foods were collated from the 2003/2004 New Zealand Total Diet Survey ${ }^{(16)}$, ESR (Institute of Environmental Science and Research Ltd) Client Reports ${ }^{(17,18)}$ and the New Zealand Food Composition Database ${ }^{(19)}$. Iodine concentration was calculated from simple recipes for a few common combination dishes or snacks (pasta dishes with cheese, tomato, or cheese and tomato; bread with cheese, meat, fish or fruit). Where data were retrieved from multiple sources, a weighted mean was calculated that accounted for different numbers of samples in different studies.

\section{Modelling iodine intake}

Food descriptors from the 1997 NNS and 2002 CNS were mapped to the 266 foods for which iodine concentration data were available. Where there was no direct match, the food descriptor was mapped to the most similar food with regard to the potential iodine source in the food of interest. For example, 'French stick' in the NNS was mapped to 'white bread' and 'cheesecake' was mapped to 'dairy dessert'. Furthermore, the proportion for each food descriptor that equated to the mapped food was determined. For most cases this was $1 \cdot 0$. However, when a food of interest was only a component of a described item, such as the bread component of a filled roll, an estimate of the proportion of the food most likely to contribute to iodine intake was specified, based on standard recipes. For example, the iodine concentration for 'Pita bread with vegetable' was mainly from the pita bread, mapped to bread, with a proportion of 0.75 to allow for the non-bread component. For a few food descriptors namely bitters, blancmange, curry paste, curry powder, dietary supplement, gelatine, malt drink, mustards, powdered meal substitute, relish, seeds (caraway/mixed/mustard/ poppy/pumpkin/sesame/sunflower), tahini, vinegar and wasabi, no match was obvious. Since none of these foods were considered to be significant sources of iodine based on an understanding of iodine sources and quantities consumed, they were not included in the intake estimates.

Estimates of iodine intake were made by combining mean iodine concentrations with individual $24 \mathrm{~h}$ dietary recall information from the NNS and CNS. Consumption information for each food consumed by each respondent was combined with concentration data using Microsoft FoxPro software (Microsoft Corporation, Redmond, WA, USA). Intakes were summed over all foods for each respondent to estimate a daily intake per individual. Repeat intake estimates were determined for a proportion (14-19\%, depending on population group) of respondents for whom repeat $24 \mathrm{~h}$ dietary recall data were available.

The BestFit function in the Excel add-in @Risk (Palisades Corporation, Ithaca, NY, USA) was used to determine the parametric distribution most closely representing the distribution of dietary iodine intakes (Fig. 1). The software uses a maximum likelihood estimation algorithm.

\section{Predictive intervention modelling}

Available concentration data for iodine in retail bread predate mandatory use of iodized salt in bread manufacture. The potential impact of replacing non-iodized salt in bread with iodized salt was modelled by substituting the concentration value of iodine in white, wholemeal and grain bread with those obtained from iodine fortification trial studies for salt iodized at $25-65 \mathrm{mg}$ iodine $/ \mathrm{kg}$ salt ${ }^{(20)}$. Revised iodine concentrations were derived for bread products included in the new food standard ${ }^{(8)}$ (e.g. bagels and English style muffins) and for bread-containing recipes (cheese-, fish-, meat- and fruit-containing sandwiches 
and rolls; see Appendix). Dietary iodine intakes were re-calculated for each population group with the revised iodine concentrations.

The impact of increasing the level of iodine in salt, from an average of $50 \mathrm{mg}$ iodine/ $\mathrm{kg}$ salt to $100 \mathrm{mg}$ iodine/ kg salt, was similarly modelled by doubling the additional iodine content of regulated breads and bread products used in intake calculations.

Dietary advice with respect to food sources of iodine ${ }^{(10)}$ was tested by estimating the amount of any one of the recommended foods (seafood, seameal custard, milk and eggs), or iodized salt, that an individual with low dietary iodine intake would need to eat on a daily basis to make up the estimated iodine shortfall and thus achieve an adequate daily intake of iodine. The selected foods were assumed to contain an average concentration of iodine. The intake of the 5 th percentile was used to represent a low dietary iodine intake. The base case assumed manufacture of bread with salt iodized at $50 \mathrm{mg}$ iodine $/ \mathrm{kg}$ salt.

The potential impact on pregnant women of consuming the recommended iodine supplementation ${ }^{(11)}$ was assessed by adding $150 \mu \mathrm{g}$ to the estimated daily intakes for each of the pregnant women identified in the NNS ( $n$ 64) and comparing this with nutrient reference values for this population group ${ }^{(1)}$. Intakes assumed that bread and bread products were manufactured with iodized salt. Intakes were weighted to the New Zealand population.

\section{Risk characterization}

The adequacy of iodine intakes was assessed by comparison with Australian and New Zealand reference health standards for Estimated Average Requirements (EAR) and Upper Limits of intake (UL), derived for each population group on the basis of international and New Zealand studies (Table 1$)^{(1)}$.

\section{Statistical analysis}

Nutrient intakes based on single-day records of food consumption do not account for possible within-person variation in day-to-day iodine intake ${ }^{(21,22)}$. The software PC-SIDE version 1.0 (2003; Iowa State University, Ames, IA, USA) was used to estimate usual (long-term) iodine intakes. The software separates between- and withinperson variation, using a subsample of the population with more than one day of consumption data, as in the NNS and CNS, to estimate the within-person component of the variation. The distribution of usual intakes is the between-person variation component. PC-SIDE was used to determine summary statistics (means, medians, 5th and 95th percentiles), and proportions of iodine intakes less than adequate and greater than upper nutrient reference values, for selected population groups. Intakes for each population group were weighted to the New Zealand population at the time that the survey was conducted. The variability of intakes was represented by the 5 th and 95th percentile usual intakes for each population group.
Where there were insufficient replicate data (for pregnant women), intra- and inter-variability data for non-pregnant females was applied to estimate usual intakes for pregnant females, as described elsewhere ${ }^{(23)}$.

\section{Results}

\section{Concentration of iodine in foods}

The mean concentration of iodine in 266 foods ranged from $0.001 \mathrm{mg} / \mathrm{kg}$ in instant coffee and fruit drink to $428 \mathrm{mg} / \mathrm{kg}$ in seaweed (Appendix). Most foods contained less than $1 \mathrm{mg}$ iodine $/ \mathrm{kg}$, with the exception of five foods: seaweed, iodized salt, scallops, mussels and 'other' shellfish.

\section{Estimated dietary iodine intake}

Estimates of usual iodine intake for the six selected population groups are shown in Table 1 . Selected percentile consumers, including median, low ( 5 th percentile) and high (95th percentile), as well as mean intakes are presented to show the distribution and variability of iodine intake for each population group. Low intakes (5th percentile) ranged from 21 to $39 \mu \mathrm{g} / \mathrm{d}$ across the six groups, representing at best $39 \%$ of the EAR for 19-24year-old males and at worst $21 \%$ of the EAR for nonpregnant females. Mean and median intakes were below the respective EAR for all population groups with the exception of the mean for $\geq 25$-year-old males. Median iodine intakes ranged from 42 to $67 \mu \mathrm{g} / \mathrm{d}$, representing at best $67 \%$ of the EAR (9-13-year-old boys/girls, $\geq 25$-yearold males). The median intake for pregnant women was $50 \mu \mathrm{g} / \mathrm{d}, 31 \%$ of the EAR. For each population group, the median was less than the mean, indicative of rightskewed distributions of intake. The 95th percentile intakes were $86-148 \mu \mathrm{g} / \mathrm{d}$ across the population groups, representing 61 to $149 \%$ of the EAR and well below the UL. The distribution of usual intakes is shown graphically (Fig. 1) for one population group, $\geq 15$-year-old females (non-pregnant). The cumulative probability values to the left of the EAR represent the proportion of the population with an intake less than the EAR. When non-iodized salt is used in bread manufacture, $90 \%$ of the non-pregnant women were estimated to have iodine intakes below the EAR. When iodized salt is used, this percentage is estimated to drop to $27 \%$.

\section{Impact of iodized salt in bread}

The modelled use of iodized salt in bread manufacture had a positive impact on usual iodine intake for each of the six population groups considered (Table 1, $50 \mathrm{mg}$ iodine $/ \mathrm{kg}$ salt). The median iodine intake estimate more than doubled and exceeded the EAR for all population groups except the $\geq 15$-year-old pregnant females (Fig. 2). The proportion of consumers estimated within the recommended intake range, i.e. above the EAR and 
Table 1 Estimates of usual iodine intake based on $24 \mathrm{~h}$ diet recall and impact of using salt (iodized at 50 or $100 \mathrm{mg} / \mathrm{kg}$ ) in bread manufacture on the adequacy of usual iodine intakes for six population groups in New Zealand (excluding discretionary salt and iodine supplements)

\begin{tabular}{|c|c|c|c|c|c|c|c|c|c|c|c|c|c|c|c|c|c|c|}
\hline & \multicolumn{3}{|c|}{$\begin{array}{l}\text { 5-8-year-old } \\
\text { children }\end{array}$} & \multicolumn{3}{|c|}{$\begin{array}{c}9-13 \text {-year-old } \\
\text { boys/girls }\end{array}$} & \multicolumn{3}{|c|}{$\begin{array}{c}\geq 15 \text {-year-old females } \\
\text { (non-pregnant) }\end{array}$} & \multicolumn{3}{|c|}{$\begin{array}{c}\geq 15 \text {-year-old females } \\
\text { (pregnant) }^{\star}\end{array}$} & \multicolumn{3}{|c|}{$\begin{array}{l}\text { 19-24-year-old } \\
\text { males }\end{array}$} & \multicolumn{3}{|c|}{$\begin{array}{l}\geq 25 \text {-year-old } \\
\text { males }\end{array}$} \\
\hline $\begin{array}{l}n \\
\text { EAR }(\mu \mathrm{g} / \mathrm{d}) \\
\text { UL }(\mu \mathrm{g} / \mathrm{d})\end{array}$ & \multicolumn{3}{|c|}{$\begin{array}{c}65 \\
300\end{array}$} & \multicolumn{3}{|c|}{$\begin{array}{c}75 \\
600\end{array}$} & \multicolumn{3}{|c|}{$\begin{array}{c}100 \\
1100\end{array}$} & \multicolumn{3}{|c|}{$\begin{array}{c}160 \\
900-1100+\end{array}$} & \multicolumn{3}{|c|}{$\begin{array}{c}100 \\
1100\end{array}$} & \multicolumn{3}{|c|}{$\begin{array}{c}100 \\
1100\end{array}$} \\
\hline \multirow[t]{2}{*}{ Level of iodization } & \multicolumn{3}{|c|}{$\mathrm{mg}$ iodine/kg salt } & \multicolumn{3}{|c|}{$\mathrm{mg}$ iodine/kg salt } & \multicolumn{3}{|c|}{ mg iodine/kg salt } & \multicolumn{3}{|c|}{$\mathrm{mg}$ iodine/kg salt } & \multicolumn{3}{|c|}{$\mathrm{mg}$ iodine/kg salt } & \multicolumn{3}{|c|}{ mg iodine/kg salt } \\
\hline & 0 & 50 & 100 & 0 & 50 & 100 & 0 & 50 & 100 & 0 & 50 & 100 & 0 & 50 & 100 & 0 & 50 & 100 \\
\hline Mean $(\mu \mathrm{g} / \mathrm{d})$ & 50 & 108 & 165 & 69 & 133 & 197 & 59 & 148 & 238 & 57 & 148 & 240 & 67 & 165 & 265 & 97 & 217 & 338 \\
\hline Median $(\mu \mathrm{g} / \mathrm{d})$ & 42 & 100 & 154 & 50 & 111 & 171 & 44 & 127 & 209 & 50 & 141 & 224 & 66 & 159 & 261 & 67 & 190 & 314 \\
\hline 5th Percentile $(\mu \mathrm{g} / \mathrm{d})$ & 22 & 54 & 78 & 29 & 70 & 103 & 21 & 66 & 100 & 28 & 85 & 133 & 39 & 86 & 149 & 34 & 129 & 207 \\
\hline 95th Percentile $(\mu \mathrm{g} / \mathrm{d})$ & 97 & 197 & 306 & 86 & 189 & 299 & 140 & 269 & 450 & 97 & 263 & 459 & 105 & 289 & 449 & 148 & 292 & 498 \\
\hline$\%$ below EAR & 86 & 12 & 2 & 91 & 8 & 1 & 90 & 27 & 5 & 100 & 63 & 0 & 93 & 11 & 0 & 81 & 0 & 0 \\
\hline$\%$ between EAR and UL & 13 & 87 & 93 & 9 & 92 & 99 & 10 & 73 & 95 & 0 & 37 & 100 & 7 & 89 & 100 & 19 & 100 & 100 \\
\hline$\%$ above UL & 1 & 1 & 5 & 0 & 0 & 0 & 0 & 0 & 0 & 0 & 0 & 0 & 0 & 0 & 0 & 0 & 0 & 0 \\
\hline
\end{tabular}

$n$, number of respondents in $24 \mathrm{~h}$ diet recall survey; EAR, Estimated Average Requirement for iodine ${ }^{(1)}$; UL, Upper Limit of intake.

.

tUL is $900 \mu \mathrm{g} / \mathrm{d}$ for $14-18$-year-old females $(n 1)$; for all females over 19 years, $U \mathrm{~L}=1100 \mu \mathrm{g} / \mathrm{d}^{(1)}$.
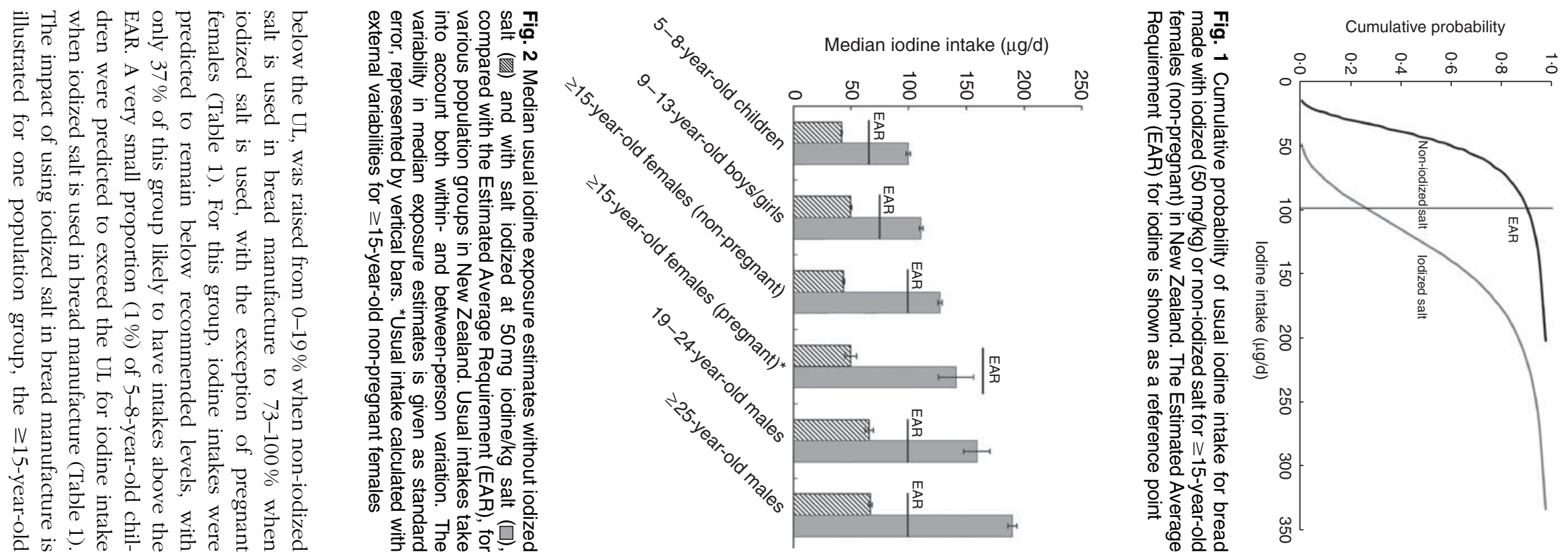
Table 2 Amount of any one selected food needed, daily, to increase iodine intake for 5 th percentile consumers to the EAR, assuming all bread is manufactured with salt iodized at $50 \mathrm{mg} / \mathrm{kg}$

\begin{tabular}{|c|c|c|c|c|c|c|}
\hline & $\begin{array}{l}\text { 5-8-year-old } \\
\text { children }\end{array}$ & $\begin{array}{l}\text { 9-13-year-old } \\
\text { boys/girls }\end{array}$ & $\begin{array}{c}\geq 15 \text {-year-old females } \\
\text { (non-pregnant) }\end{array}$ & $\begin{array}{c}\geq 15 \text {-year-old } \\
\text { females (pregnant)* }\end{array}$ & $\begin{array}{l}\text { 19-24-year-old } \\
\text { males }\end{array}$ & $\begin{array}{l}\geq 25 \text {-year-old } \\
\text { males }\end{array}$ \\
\hline Shortfall $(\mu \mathrm{g} / \mathrm{d})$ & 11 & 5 & 34 & 75 & 14 & 0 \\
\hline Low-fat milk (ml) & 115 & 52 & 354 & 781 & 146 & 0 \\
\hline Yoghurt (g) & 133 & 60 & 410 & 904 & 169 & 0 \\
\hline Eggst & 0 & 0 & 1 & 3 & 1 & 0 \\
\hline Fish $(g) \ddagger$ & 40 & 18 & 123 & 271 & 51 & 0 \\
\hline Shellfish $(\mathrm{g}) \S$ & 6 & 3 & 17 & 38 & 7 & 0 \\
\hline Salt, iodized $(g) \|$ & $0 \cdot 2$ & $0 \cdot 1$ & $0 \cdot 7$ & $1 \cdot 5$ & 0.3 & 0 \\
\hline
\end{tabular}

EAR, Estimated Average Requirement for iodine ${ }^{(1)}$

Shortfall is the difference between iodine intake of low consumers (5th percentile) and the EAR for various population groups.

${ }^{\star}$ Excluding recommended $150 \mu \mathrm{g}$ supplement. If low consuming pregnant women consume the recommended $150 \mu \mathrm{g}$ iodine supplement, they would achieve an adequate iodine intake without additional food sources.

tAssuming $1 \mathrm{egg}$ weighs $50 \mathrm{~g}$ and iodine concentration $=0.519 \mathrm{mg} / \mathrm{kg}$.

¥Fish, assumed iodine concentration $=0.277 \mathrm{mg} / \mathrm{kg}$.

$\S$ Shellfish, assumed iodine concentration $=2 \cdot 0 \mathrm{mg} / \mathrm{kg}$.

IISalt, iodized, assumed iodine concentration $=50 \mathrm{mg} / \mathrm{kg}$.

females (non-pregnant) in Fig. 1. For this group, the percentage of the population achieving the EAR increased from 10 to $73 \%$ of respondents.

\section{Food consumption to meet iodine intake shortfalls}

The amount of any one of the foods recommended as a source of iodine that would need to be eaten on a daily basis to increase iodine intake to the EAR, for a low iodine intake consumer ( 5 th percentile), is shown in Table 2. The amount of salt, iodized at $50 \mathrm{mg} / \mathrm{kg}$, required to achieve the same iodine intake is also included.

\section{Impact of furtber increasing the level of iodine in salt}

When the intake model was adjusted to include an iodine content in salt used for bread manufacture twice that currently used (increased from 50 to $100 \mathrm{mg}$ iodine $/ \mathrm{kg}$ salt), the proportion of population groups with adequate iodine intakes increased from $37-100 \%$ to $93-100 \%$ (Table 1), with the largest increase estimated for pregnant women. For this scenario, the maximum proportion of consumers that might exceed the upper limit for iodine was $5 \%$ for $5-8$-year-old children.

\section{Impact of supplementation for pregnant women}

When $150 \mu \mathrm{g}$ was added to the estimated usual daily intakes for the pregnant women identified in the NNS ( $n$ 64), assuming bread and bread products were manufactured with salt iodized at either $50 \mathrm{mg}$ or $100 \mathrm{mg}$ iodine/ $\mathrm{kg}$ salt, all respondents achieved adequate estimated iodine intakes. No respondents were predicted to exceed the UL for either scenario.

\section{Discussion}

The low mean iodine intakes estimated in the present study, when non-iodized salt is used in bread and bread products, generally confirmed those previously reported that were based on simulated diets, where population groups were matched ${ }^{(3)}$.

While the exposure methodology described in the present study provides a realistic estimate of iodine intake for the selected population groups, and more information than deterministic modelling based on simulated diets, there are recognized limitations. First, the 266 foods included in the study were mapped to over 5000 foods described in the NNS/CNS, requiring assumptions that mapped foods have similar iodine concentrations to the analysed foods. There is a measure of uncertainty around these assumptions. Second, while each of the 266 foods has a range of iodine concentrations, only mean concentration data were applied. However, this is a valid approach if long-term usual intakes are the parameter of interest $^{(24)}$. The accuracy of an exposure assessment is dependent on the accuracy of the concentration data used. The majority of concentration data (77\%) were sourced from analytical surveys of retail foods commissioned by the Ministry of Agriculture and Forestry ${ }^{(3,17,18)}$. Robustness of these data was substantiated by quality assurance data for blanks, spikes, duplicates and Certified Reference samples. Quality assurance of data from the Food Composition Tables (23\% of foods) ${ }^{(19)}$ was not available. A further limitation relates to under-reporting of food intake. Under-reporting is a commonly recognized problem with self-reported dietary surveys such as $24 \mathrm{~h}$ dietary recall ${ }^{(25)}$ and applies particularly to foods that may be perceived as 'bad', for example alcohol and fats. Although this phenomenon is usually referred to as under-reporting, in some cases it may be under-eating. Conversely, foods perceived to be socially acceptable (e.g. fruits and vegetables) may be over-reported ${ }^{(21)}$. An analysis of under-reporting in the NNS concluded that $12 \%$ of men and $21 \%$ of women surveyed were 'definite' under-reporters, with ratios of energy intake to RMR of less than $0.9^{(26)}$. Given that bread, marine and dairy foods accounted for the majority of dietary iodine and these would be seen as neutral foods, there is no reason to 
expect under-reporting to be especially problematic for the iodine exposure assessments presented. There may be some under-reporting of beer, perceived as 'bad', but given that beer accounted for at most $6 \%$ of iodine intake for the 19-24-year-old males when non-iodized salt was used in bread manufacture, the impact of any underreporting is likely to be minor (less than $1 \%$ of intake). It should be noted that the consumption information for New Zealand adults is now 13 years old and may not reflect more recent eating behaviours.

While the intervention to use iodized salt in bread is expected to raise dietary iodine intakes, modelling suggests that between 8 and $63 \%$ of each population group are predicted to have an inadequate iodine intake, excluding any contribution from use of iodized salt in cooking or at the table. More commonly consumed good food sources of iodine are low-fat milk, yoghurt, eggs, fish and shellfish (Appendix). For a $\geq 15$-year-old female (non-pregnant) at the 5 th percentile of iodine intake to achieve a recommended intake of iodine, she would need to consume up to $354 \mathrm{ml}$ low-fat milk, $410 \mathrm{~g}$ yoghurt, an egg, $123 \mathrm{~g}$ fish or $17 \mathrm{~g}$ shellfish every day in addition to her usual diet. Of course, a combination of foods may be consumed to the same end. With the exception of the $\geq 25$-year-old males, the consumption amounts necessary to raise a low iodine intake to the recommended level may be challenging for some consumers. On the other hand, an adequate level of iodine intake may be achieved from the consumption of $0 \cdot 1$ to $1.5 \mathrm{~g}$ of iodized salt, equivalent to one pinch to one-third of a teaspoon of salt daily.

Predictive modelling suggests that a small proportion of 5-8-year-old children (1\%) might exceed the UL when bread is manufactured with salt iodized at $50 \mathrm{mg}$ iodine/ $\mathrm{kg}$ salt. This prediction is based on twenty-three respondents with intakes ranging from $1 \cdot 1$ to 13 times the UL. Intake of the two extreme consumers in this group was dominated by the consumption of $9 \mathrm{~g}$ seaweed and in excess of $500 \mathrm{ml}$ fish soup, respectively. The fish soup was mapped to 'shellfish, other' and is likely to be an overestimate as a significant proportion of the soup is water that will not contribute iodine. For most of the twenty-three respondents however, the high iodine intake was from bread consumption, with or without eggs. The proportion of high exposures rises to $5 \%$ when a higher level of iodization is applied. Thus, a small proportion of 5-8-year-old children are likely to have intakes in excess of the UL.

In recognition of the difficulty of women of childbearing age achieving sufficient iodine intake from food alone, even with the mandatory use of iodized salt in bread, the New Zealand Ministry of Health recommends that pregnant and breast-feeding women take a registered $150 \mu \mathrm{g}$ iodine tablet ${ }^{(11)}$. When daily intake of such a supplement is added to the modelled baseline usual dietary iodine intakes for pregnant women, most pregnant women (99\%) are predicted to achieve adequate iodine intakes and less than $0.5 \%$ are predicted to exceed the UL for iodine. This excludes any contribution from discretionary use of iodized salt.

Although food regulations allow a range of $25-65 \mathrm{mg}$ iodine $/ \mathrm{kg}$ salt, the average concentration of iodine in iodized retail salts available in New Zealand is $50 \mathrm{mg} / \mathrm{kg}^{(27)}$. Internationally, the iodine concentration of fortified salt is in the range 13 to $100 \mathrm{mg} / \mathrm{kg}$. In the USA, where iodized salt constitutes approximately $50-60 \%$ of the market, salt is iodized at $100 \mathrm{mg} / \mathrm{kg}^{(28)}$. If the level of iodization of salt used for bread manufacture in New Zealand were to be doubled, to a mean concentration of $100 \mathrm{mg}$ iodine $/ \mathrm{kg}$ salt, the proportion of selected population groups achieving an adequate iodine intake is predicted to increase from $37-100 \%$ to $93-100 \%$. At the higher rate of iodization, about $5 \%$ of 5-8-year-old children might exceed the UL for iodine, excluding any contribution from salt added at cooking or at the table.

Quantitative data on discretionary use in New Zealand is not available. Hence the intake estimates presented exclude any addition from iodized salt added at the time of cooking or at the table. Based on dietary information from the NNS and CNS, approximately $60 \%$ of New Zealanders might be expected to add salt when cooking $^{(14,15)}$. This would more likely be iodized salt than not, adding to iodine intake for these consumers. Drawing on the work of Mattes and Donnelly that salt added during cooking accounted for $5 \cdot 1 \%$ of total dietary $\mathrm{Na}$ (thus $511 \mathrm{mg}$ salt $)^{(29)}$, that this salt is iodized at $50 \mathrm{mg}$ iodine $/ \mathrm{kg}$ salt, and assuming a third of salt added during cooking is ingested $^{(30)}$, the mean contribution of iodine from salt added during cooking is of the order of $5 \mu \mathrm{g} / \mathrm{d}$. This represents $2-3 \%$ of the estimated mean daily adult intakes (Table 1). A smaller percentage, approximately 50\%, might be expected to add iodized salt at the table (unpublished data from 2002 CNS). Assuming table salt accounts for $6 \cdot 2 \%$ of dietary $\mathrm{Na}$ (thus $621 \mathrm{mg}$ salt) ${ }^{(29)}$, the mean contribution of iodine, for those who add salt at the table, is approximately $30 \mu \mathrm{g} / \mathrm{d}$. This represents an additional $14-21 \%$ of iodine intake for those adults who add salt, or $7-10 \%$ to mean population intakes. A proportion of New Zealanders would be expected to have no additional iodine from iodized salt, either from cooking (approximately 30\%) or at the table (approximately 50\%).

Data on iodine-containing supplement use in New Zealand is not readily available and the relative contribution of iodine from this source is unknown. The current estimations will be refined with quantitative data for discretionary salt and iodine supplement usage.

\section{Acknowledgements}

This work was supported with funding from the New Zealand Research Science \& Technology CRI Capability 
Fund, 2009/2010. There are no conflicts of interest for any of the authors. The authors' responsibilities were as follows: B.M.T. designed the research, conducted the PC-SIDE analysis and had primary responsibility for the final content; S.S. conducted the exposure assessments and contributed to writing the paper; P.J.C. contributed to the analysis and paper writing. The authors wish to acknowledge the Ministry of Health as owner of the copyright and funders of the 1997 National Nutrition Survey and the 2002 National Children's Nutrition Survey and to thank them for access to food consumption information $(24 \mathrm{~h}$ dietary recall and qualitative FFQ) from these surveys. They also thank Beverley Horn, Richard Vannoort and Stephen On for their constructive review of the paper.

\section{References}

1. National Health and Medical Research Council (2006) Nutrient Reference Values for Australia and New Zealand Including Recommended Dietary Intakes. Canberra/ Wellington: National Health and Medical Research Council/ Ministry of Health.

2. Thomson CD (2004) Selenium and iodine intakes and status in New Zealand and Australia. BrJ Nutr 91, 661-672.

3. Thomson BM, Vannoort RW \& Haslemore RM (2008) Dietary exposure and trends of exposure to nutrient elements iodine, iron, selenium and sodium from the 2003-4 New Zealand Total Diet Survey. Br J Nutr 99, 614-625.

4. Skeaff SA, Ferguson EL, McKenzie JE et al. (2005) Are breast-fed infants and toddlers in New Zealand at risk of iodine deficiency? Nutrition 21, 325-331.

5. Skeaff SA, Thomson CD \& Gibson RS (2002) Mild iodine deficiency in a sample of New Zealand schoolchildren. Eur J Clin Nutr 56, 1169-1175.

6. Thomson CD (2003) The declining iodine status of New Zealanders: reasons, consequences and possible solutions. Proc Nutr Soc NZ 28, 35-42.

7. Thomson CD, Colls AJ, Conaglen JV et al. (1997) Iodine status of New Zealand residents as assessed by urinary iodide excretion and thyroid hormones. Br J Nutr 78, 901-912.

8. Food Standards Australia New Zealand (2010) Australia New Zealand Food Standards Code, Standard 2.1.1. Cereals and cereal products. http://www.foodstandards.gov.au/_srcfiles/ Standard_2_1_1_Cereals_v1031.pdf (accessed May 2010).

9. World Health Organization (2008) Salt as a Vehicle for Fortification. Report of a WHO Expert Consultation, Luxembourg, 21-22 March 2007. Geneva: WHO.

10. Ministry of Health (2009) Nutrition, Iodine status in New Zealand. http://www.moh.govt.nz/moh.nsf/indexmh/nutritioniodine (accessed March 2010).

11. Ministry of Health (2010) Maternity. Supplement (tablet) to take when pregnant or breastfeeding. http://www.moh. govt.nz/moh.nsf/indexmh/pregnancy-supplement (accessed May 2010).

12. Green T, Newton R \& Bourn D (2003) Estimated folic acid intakes from simulated fortification of the New Zealand food supply. N Z Med J 116, U294.
13. Hamner HC, Mulinare J, Cogswell ME et al. (2009) Predicted contribution of folic acid fortification of corn masa flour to the usual folic acid intake for the US population: National Health and Nutrition Examination Survey 2001-2004. Am J Clin Nutr 89, 305-315.

14. Russell DG, Parnell WR, Wilson NC et al. (1999) NZ Food: NZ People. Wellington: Ministry of Health.

15. Ministry of Health (2003) NZ Food NZ Children. Key Results of the 2002 National Children's Nutrition Survey. Wellington: Ministry of Health.

16. Vannoort RW \& Thomson BM (2005) 2003/04 New Zealand Total Diet Survey. Agricultural Compound Residues, Selected Contaminants and Nutrients. Wellington: New Zealand Food Safety Authority.

17. Thomson BM (2005) Iodine in Seaweed Containing Foods. ESR Client Report FW0516. Christchurch: Institute of Environmental Science and Research Ltd.

18. Love JL \& Jones S (2006) Iodine in New Zealand Food. ESR Client Report FW0631. Christchurch: Institute of Environmental Science and Research Ltd.

19. Crop \& Food Reseach (2006) FOODfiles 2006. http:// www.crop.cri.nz/home/products-services/nutrition/food compdata/fcd-products/fcd-foodfiles/index.php (accessed May 2010).

20. Thomson BM (2009) Stability of added iodine in processed cereal foods. Food Addit Contam Part A Chem Anal Control Expo Risk Assess 26, 25-31.

21. Carriquiry AL (2003) Estimation of usual intake distributions of nutrients and foods. J Nutr 133, issue 2, 601S-608S.

22. Dodd KW, Guenther PM, Freedman LS et al. (2006) Statistical methods for estimating usual intake of nutrients and foods: a review of the theory. J Am Diet Assoc 106, $1640-1650$.

23. Jahns L, Arab L, Carriquiry AL et al. (2005) The use of external within-person variance estimates to adjust nutrient intake distributions over time and across populations. Public Health Nutr 8, 69-76.

24. Kroes R, Muller D, Lambe J et al. (2002) Assessment of intake from the diet. Food Chem Toxicol 40, 327-385.

25. Black AE (2000) Critical evaluation of energy intake using the Goldberg cut-off for energy intake:basal metabolic rate. A practical guide to its calculation, use and limitations. Int J Obes Relat Metab Disord 24, 1119-1130.

26. Pikholz C, Swinburn B \& Metcalf P (2004) Under-reporting of energy intake in the 1997 National Nutrition Survey. $N Z$ Med J 117, U1079.

27. Thomson BM (2009) Levels of iodine in New Zealand retail salt, ESR Client Report FW09060. http://www.nzfsa.govt. nz/science/research-projects/FW09060_Iodine_in_NZ_retail_ salt.pdf (accessed March 2010).

28. Food Standards Australia New Zealand (2007) Consideration on mandatory fortification with iodine for Australia and New Zealand. International experience with iodine fortification programs (SD6). http://www.foodstandards. govt.nz/foodstandards/proposals/proposalp1003mandato 3882.cfm (accessed May 2010).

29. Mattes RD \& Donnelly D (1991) Relative contributions of dietary sodium sources. J Am Coll Nutr 10, 383-393.

30. Sánchez-Castillo CP \& James WP (1995) Defining cooking salt intakes for patient counselling and policy making. Arch Latinoam Nutr 45, 259-264. 
Appendix

Consolidated data of mean iodine concentration in New Zealand foods (mg/kg)

\begin{tabular}{|c|c|c|c|c|c|c|c|c|}
\hline Food & Mean (mg/kg) & $\operatorname{Ref}^{*}$ & Food & Mean $(\mathrm{mg} / \mathrm{kg})$ & $\operatorname{Ref}^{*}$ & Food & Mean (mg/kg) & $\operatorname{Ref}^{*}$ \\
\hline Apple & 0.002 & 1 & Chutney & 0.003 & 3 & Pancake & 0.271 & 4 \\
\hline Apple-based juice & 0.009 & 1 & Coconut & 0.010 & 4 & Papaya & 0.043 & 4 \\
\hline Apricot, canned & 0.015 & 1 & Coffee beans, ground & 0.001 & 1 & Pasta dish, cheese & 0.057 & 1,3 \\
\hline Avocado & 0.001 & 1 & Coffee, instant & 0.001 & 1 & Pasta dish, other & 0.043 & 1,3 \\
\hline Bacon & 0.011 & 1 & Confectionery & 0.008 & 1 & Pasta dish, tomato & 0.014 & 1,3 \\
\hline Bagel, plain & 0.012 & 4 & Cookies, other & 0.043 & 4 & Pasta, dried & 0.015 & 1 \\
\hline Bagel, plain, iodized & $1 \cdot 400$ & 5 & Corn, canned & 0.008 & 1 & Pâté, chicken & 0.014 & 3 \\
\hline Bagel, wheat & 0.005 & 4 & Corned beef & 0.025 & 1 & Pâté, meat & 0.068 & 3 \\
\hline Bagel, wheat, iodized & 0.583 & 5 & Cornflakes & 0.011 & 1,3 & Pâté, seafood & 0.040 & 3 \\
\hline Banana & 0.001 & 1 & Cornflakes, coco pops & 0.025 & 3 & Peaches, canned & 0.013 & 1 \\
\hline Beans & 0.001 & 1 & Cornflakes, rice bubbles & $0 \cdot 010$ & 3 & Peanuts, whole & 0.011 & 1 \\
\hline Beans, baked, canned & 0.016 & 1 & Courgette & 0.002 & 1 & Pear & 0.001 & 1 \\
\hline Beef, mince & 0.010 & 1 & Crab & 0.275 & 3 & Peas & 0.001 & 1 \\
\hline Beef, rump & 0.007 & 1 & Crayfish & 0.286 & 3 & Pesto & 0.060 & 4 \\
\hline Beer & 0.013 & 1 & Cream & 0.061 & 1 & Pickle & 0.015 & 3 \\
\hline Beetroot, canned & 0.023 & 1 & Cream, reduced & $0 \cdot 195$ & 3 & Pie, chicken & 0.020 & 4 \\
\hline Biscuit, afghan & 0.035 & 3 & Cream, sour & 0.055 & 3 & Pie, fruit & 0.004 & 4 \\
\hline Biscuit, arrowroot & 0.010 & 4 & Cucumber & 0.001 & 1 & Pie, meat & 0.008 & 1 \\
\hline Biscuit, chocolate & 0.060 & 1,3 & Curry, other & 0.233 & 4 & Pineapple, canned & 0.015 & 1 \\
\hline Biscuit, chocolate chip & 0.045 & 3 & Custard, other & $0 \cdot 198$ & 4 & Pizza & 0.031 & 1 \\
\hline Biscuit, chocolate wheaten & 0.035 & 3 & Dairy dessert & 0.067 & 1 & Popcorn & 0.005 & 4 \\
\hline Biscuit, cracker & 0.008 & 1 & Dates, dried & 0.015 & 4 & Pork chop & 0.009 & 1 \\
\hline Biscuit, cracker, rice & $0 \cdot 180$ & 4 & Dip, other & 0.057 & 4 & Pork, salami & 0.010 & 3 \\
\hline Biscuit, macaroons & 0.030 & 3 & Dumpling & 0.006 & 4 & Pork, saveloy & 0.077 & 3 \\
\hline Biscuit, mallowpuffs & 0.080 & 3 & Egg & 0.519 & 1 & Potato crisps & 0.013 & 1 \\
\hline Biscuit, plain sweet & $0 \cdot 016$ & 1 & Figs, dried & $0 \cdot 010$ & 4 & Potato, hot chips & 0.041 & 1,3 \\
\hline Biscuit, Tim tams & $0 \cdot 140$ & 3 & Fish cake & 0.021 & 3 & Potato, hot chips, fast-food chains & 0.002 & 3 \\
\hline Biscuit, wafers & 0.032 & 4 & Fish fingers & 0.032 & 1 & Potato, hot chips, frozen & 0.004 & 3 \\
\hline Biscuit, wine & 0.010 & 3 & Fish, battered & $0 \cdot 166$ & 1 & Potato, hot chips, takeaway & 0.004 & 3 \\
\hline Blackberry & 0.002 & 4 & Fish, canned & $0 \cdot 130$ & 1 & Potato, scalloped & 0.014 & 4 \\
\hline Bran flake cereal, mixed & 0.010 & 1 & Fish, crustaceans & 0.849 & 3 & Potato, wedge & 0.010 & 4 \\
\hline Bread, cheese & 0.048 & 1,3 & Fish, fresh & 0.277 & 1,3 & Potatoes, peeled & 0.003 & 1 \\
\hline Bread, cheese, iodized & 0.280 & 5 & Fish, hoki & 0.244 & 3 & Potatoes, with skin & 0.011 & 1 \\
\hline Bread, crumpets & 0.010 & 3 & Fish, orange roughy & 0.429 & 4 & Prunes & 0.008 & 1 \\
\hline Bread, donut plain & 0.030 & 3 & Fish, salmon & 0.274 & 3 & Pumpkin & 0.004 & 1 \\
\hline Bread, fish & $0 \cdot 102$ & 1,3 & Fish, snapper & 0.565 & 3 & Quiche & $0 \cdot 166$ & 3 \\
\hline Bread, fish, iodized & 0.493 & 5 & Fish, surimi & 0.065 & 3 & Raisins, yoghurt coated & $0 \cdot 118$ & 4 \\
\hline Bread, fruit & 0.002 & 1,3 & Fish, tarakihi & 0.484 & 3 & Raisins/sultanas & 0.017 & 1 \\
\hline Bread, fruit, iodized & $0 \cdot 106$ & 5 & Fish, tuna & $0 \cdot 127$ & 4 & Rhubarb & 0.007 & 4 \\
\hline Bread, meat & 0.015 & 1,3 & Flour, other & 0.005 & 4 & Rice, white & 0.003 & 1 \\
\hline Bread, meat, iodized & $0 \cdot 142$ & 5 & Flour, white & 0.011 & 4 & Salad dressing & 0.036 & 1 \\
\hline Bread, mixed grain & $0 \cdot 012$ & 1 & Flour, wholemeal & 0.010 & 4 & Salad dressing, vinaigrette & 0.010 & 3 \\
\hline Bread, mixed grain, iodized & $0 \cdot 710$ & 5 & Fruit drink & 0.001 & 1 & Salt, iodized & $49 \cdot 3$ & 4 \\
\hline Bread, pastry & 0.010 & 3 & Fruit salad & 0.039 & 3 & Salt, plain & 0.390 & 4 \\
\hline Bread, soya \& linseed & 0.073 & 4 & Fruit, other & 0.005 & 1 & Sauce, other & 0.022 & 4 \\
\hline Bread, takakau & 0.057 & 4 & Ginger & 0.007 & 4 & Sausage roll & 0.080 & 4 \\
\hline
\end{tabular}




\begin{tabular}{|c|c|c|c|c|c|c|c|c|}
\hline Food & Mean $(\mathrm{mg} / \mathrm{kg})$ & $\operatorname{Ref}^{*}$ & Food & Mean $(\mathrm{mg} / \mathrm{kg})$ & $\operatorname{Ref}^{*}$ & Food & Mean (mg/kg) & $\operatorname{Ref}^{*}$ \\
\hline Bread, wheat meal & 0.005 & 1 & Gooseberry & 0.002 & 4 & Sausages & $0 \cdot 104$ & 1,3 \\
\hline Bread, wheat meal, iodized & 0.710 & 5 & Grapes & 0.005 & 1 & Sausages, vegetarian & 0.044 & 2 \\
\hline Bread, white & 0.006 & 1,3 & Gravy & 0.010 & 3 & Scallop & $2 \cdot 030$ & 4 \\
\hline Bread, white, iodized & 0.700 & 5 & Ham & 0.037 & 1 & Seaweed & $428 \cdot 0$ & 2 \\
\hline Broccoli/cauliflower & 0.001 & 1 & Hamburger, Big-Mac & 0.013 & 3 & Shellfish, other & $2 \cdot 450$ & 4 \\
\hline Butter & 0.010 & 1 & Hamburger, cheese & 0.027 & 3 & Shrimp & 0.294 & 3 \\
\hline Cabbage & 0.001 & 1 & Hamburger, plain & 0.022 & 1,3 & Silver beet & 0.027 & 1 \\
\hline Caffeinated beverage & 0.001 & 1 & Honey & 0.006 & 1 & Snack bars & 0.093 & 1,3 \\
\hline Cake & $0 \cdot 104$ & 1,3 & Hummus & 0.010 & 4 & Snacks, corn chips & $0 \cdot 010$ & 3 \\
\hline Cake, chocolate & 0.090 & 3 & Ice cream & 0.058 & 1,3 & Snacks, flavoured & 0.058 & 1 \\
\hline Cake, fruit & 0.060 & 3 & Ice cream, chocolate & 0.063 & 3 & Soup, chicken & 0.021 & 1 \\
\hline Cake, sponge & $0 \cdot 115$ & 3 & Infant \& follow-on formula & 0.079 & 1 & Soup, other & 0.012 & 4 \\
\hline Capsicum & 0.001 & 1 & Infant weaning food, cereal & 0.025 & 1 & Soya milk & $0 \cdot 008$ & 1 \\
\hline Carbonated drink & 0.002 & 1 & Infant weaning food, custard/fruit dish & 0.061 & 1 & Spaghetti in sauce, canned & 0.020 & 1 \\
\hline Carrot & 0.004 & 1 & Infant weaning food, savoury & 0.020 & 1 & Spinach & 0.031 & 4 \\
\hline Celery & 0.010 & 1 & Kiwifruit & 0.001 & 1 & Spirits & 0.005 & 4 \\
\hline Cereal & 0.012 & 1,3 & Kumara & 0.003 & 1 & Spread, jam & 0.005 & 1 \\
\hline Cheese, brie & 0.020 & 3 & Lamb/mutton & 0.032 & 1 & Spread, Nutella & $0 \cdot 130$ & 3 \\
\hline Cheese, camembert & 0.025 & 3 & Lettuce & 0.007 & 1 & Spread, peanut butter & 0.051 & 1 \\
\hline Cheese, cheddar & 0.055 & 3 & Lychee, canned & 0.008 & 4 & Spreads, sweet & 0.040 & 3 \\
\hline Cheese, Colby & 0.060 & 3 & Margarine & 0.005 & 1 & Spring roll, meat & 0.040 & 4 \\
\hline Cheese, cottage & 0.045 & 3 & Meat, other & 0.016 & 1,3 & Spring roll, vegetable & 0.000 & 4 \\
\hline Cheese, cream & 0.095 & 3 & Melons & 0.001 & 1 & Squid & 0.216 & 4 \\
\hline Cheese, edam & 0.075 & 3 & Milk, $0.5 \%$ fat & 0.096 & 1 & Stir-fry, seafood & 0.045 & 4 \\
\hline Cheese, feta & 0.255 & 3 & Milk, $3 \cdot 25 \%$ fat & 0.086 & 1 & Strawberries & 0.002 & 1 \\
\hline Cheese, gouda & 0.040 & 4 & Milk, condensed & 0.245 & 3 & Sugar & 0.005 & 1 \\
\hline Cheese, other & 0.070 & 1,3 & Milk, flavoured & 0.063 & 1,3 & Sushi & 0.043 & 4 \\
\hline Cheese, parmesan & 0.038 & 4 & Milk, goat & 0.060 & 4 & Taro & 0.006 & 1 \\
\hline Cheese, vein & 0.040 & 3 & Muesli & 0.011 & 1 & Tomato & 0.001 & 1 \\
\hline Chicken & 0.013 & 1,3 & Muesli, Nutrigrain & 0.030 & 3 & Tomato sauce & 0.014 & 1,3 \\
\hline Chicken takeaway & 0.032 & 1 & Muffin & 0.087 & 1 & Tomatoes in juice & 0.006 & 1 \\
\hline Chicken, KFC & 0.089 & 3 & Muffin, English & 0.003 & 4 & Tortilla, maize & 0.010 & 4 \\
\hline Chicken, nugget & 0.053 & 4 & Muffin, English, iodized & 0.350 & 5 & Turnip & 0.005 & 4 \\
\hline Chinese dish & 0.045 & 1 & Mushrooms & 0.003 & 1 & Vegetable, other & 0.005 & 1 \\
\hline Chocolate & $0 \cdot 168$ & 3 & Mussels & $1 \cdot 660$ & 1,3 & Venison & 0.006 & 4 \\
\hline Chocolate bar & 0.270 & 3 & Nectarine & 0.001 & 1 & Water & 0.002 & 1 \\
\hline Chocolate beverage, milk & $0 \cdot 104$ & 1 & Noodles, instant & 0.068 & 1 & Watercress & 0.027 & 4 \\
\hline Chocolate beverage, powder & 0.030 & 3 & Oats, rolled & 0.002 & 1 & Wheat biscuit cereals & 0.005 & 1 \\
\hline Chocolate beverage, water & 0.013 & 1 & Oil & 0.005 & 1 & Wine, still red & 0.009 & 1 \\
\hline Chocolate dairy dessert & 0.045 & 2 & Onion & 0.004 & 1 & Wine, still white & 0.005 & 1 \\
\hline Chocolate other, pebbles & 0.065 & 3 & Orange & 0.002 & 1 & Yeast extract & 0.055 & 1 \\
\hline Chocolate, Cadburys & $0 \cdot 114$ & 4 & Orange juice & 0.009 & 1 & Yoghurt & 0.083 & 1 \\
\hline Chocolate, plain milk & $0 \cdot 153$ & 1 & Oysters & $0 \cdot 787$ & 1,3 & & & \\
\hline
\end{tabular}

${ }^{*} 1=$ Thomson et al. ${ }^{(3)} ; 2=$ Thomson $^{(17)} ; 3=$ Love and Jones $^{(18)} ; 4=$ Crop \& Food Reseach ${ }^{(19)} ; 5=$ Thomson $^{(20)}$. 